\title{
SÔBRE A PROBLEMÁTICA: CERTEZA NO DIREITO
}

\author{
Emmanoel Augusto Perillo \\ Professor Catedrático de Introdução à Ciência do \\ Direito da Faculdade de Direito de Goiás.
}

Assinala Lopes Onate que o mundo em que vivemos está em crise de angústia por haver fracassado o seu intento de determinar o seu próprio sentido. 0 problema atual é o da certeza do Direito como antes, em face da filosofia, foi o da verdade e, na época clássica, o da realidade.

$\mathrm{Na}$ primitiva vida dos povos, o homem pesquisou a verdade, pois, procurou-se conhecer num sentido de universalidade.

Daí, o fato da existência dos antigos filósofos, aos quais se atribuiu acentuada bagagem de sabedoria, cujo significado da expressão era mesmo "amantes da sabedoria". Foram êles, enfim, os amigos do saber. A finalidade de seus estudos era a busca do verdadeiro.

O Direito era, como de resto sempre foi, um problema eminentemente humano, eis que estava envolto no conhecimento generalizado do homem antigo. Êste, como já o dissemos, buscava, nos seus estudos, a verdade antes de tudo. Destarte, o Direito constituia uma procura de ordem filosófica e, como tal, uma problemática de conhecimento.

Como maior alvo do homem, propuseram-se os mais remotos especuladores à busca do verdadeiro, não sendo pois exagêro mencionar-se como investigadores daquilo que é e do que deve ser os mais antigos estudiosos da vida humana, em sociedade. 
Assim é que, na antiga cultura Egípcia, conforme história Luno Pena, vamos encontrar as doutrinas de Menfis, as Máximas Morais de Ptahhotep, os trabalhos sôbre a sabedoria de Amenemope, Diálogo de um desesperado com a sua alma, Diálogo da Verdade e da Mentira, não podendo deixar de mencionar, como um dos trabalhos mais antigos, no gênero especulativo, o célebre "Livro dos Mortos".

De outra maneira não nos é dado considerar, na antiguidade grega, as indagações de um Heráclito, Sócrates, Platão, Aristóteles e outros.

Assim, foi o Direito, primordialmente, uma indagação de verdade, para se converter, mais tarde, na de realidade e,atualmente, pode-se considerá-lo sob o aspecto de certeza.

È êsse o prisma em que iremos procurar focalizar o que os estudiosos possam considerar como jurídico, fazendo salientar que abordaremos o assunto, senão pela sua originalidade, pelo menos por aspectos novos e que, por si so, despertem as atenções dos que estudam, na imensidade de sua riqueza, a doutrina jurídica.

Primitivamente, como já o afirmamos, os estudos e as ansiedades humanas se cingiam ao aspecto do verdadeiro, pois, que o conhecimento do homem se orientava num sentido de universalidade. $\mathrm{E}$ o que se dizia respeito à conduta social dos indivíduos envolvia-se na órbita do saber generalizado.

Daí, a circunstância de se destacarem, conforme doutrina Josef Kunz, três posições diversas para o jurídico que, assim, pode ser examinado como Direito, como filosofia do Direito e como ciência do Direito.

É Kunz quem ressalta ter havido direito sem ciência do Direito, não só nas culturas prehistóricas e nas primitivas de nossos dias, mas, também, nas antigas culturas mais elevadas, eis que o direito, como fenômeno eminente humano (ubi homo, ibi jus), é mais antigo que a ciência do Direito e, como estamos tentando demonstrar, até mesmo da filosofia jurídica.

Não havia filósofos, como desbravadores do saber humano, mas o fenômeno jurídico já era interpretado onde houvesse homem associado. 
Nesse sentido Kirchman é bastante claro quando afirma que um povo pode viver muito bem sem ciência jurídica, porém nunca sem Direito.

Chegado à culminância dos estudos filosóficos dos helenos e, em particular, da filosofia jurídica, ingressou-se num período de vida em que o jurídico já não era mais só indagação, porém, bem ao contrário, uma orientação em sentido de realismo objetivo e prático.

Os romanos, na sua grande antevisão do mundo jurídico, sentiram o Direito como ciência, através da preocupação desde logo demonstrada, na profissão dos juristas, de ordenar a conduta humana, de organizar politicamente a sociedade.

Destarte, o Direito já não era só abstração, como o caracterizou a fase grega, mas realidade traduzida em normas costumeiras e escritas. O Direito revela-se, entre os romanos, como regras imperiosas e necessárias para a vida em comunhão.

Saido de um período meramente especulativo, o Direito, face ao espírito prático dos romanos, tomava um sentido mais realístico, vale dizer, mais de ciência do que de filosofia.

Foram, assim, os romanos os primeiros a se preocuparem com a problemática, tema central dêste trabalho.

Os costumes foram a revelação de um direito orientado na base de atividade prática, na comunidade de Roma. Acontece, porém, que a regra consuetudinária teria de gerar, como de fato gerou, dada a sua própria natureza, a incerteza na sua aplicação. Daí, a fase tumultuosa por que passaram os romanos e a que se classificou de jus incertum.

A norma costumeira trouxe a incerteza, pois que, na função de disciplinar os comportamentos individuais, não foi precisa, pecou pela inexatidão, eis que o trato das coisas de Direito oferecia, então, uma face dificultosa aos antigos romanos - a de se saber a regra exata a ser observada.

Pela própria natureza de norma não escrita, os costumes, primordialmente, não foi regra certa para conduta do homem. Na dificuldade entre o uso e o desuso de determinada norma, o romano preferiu que esta se fixasse melhor, num sentido de 
certeza. Procurou-se, portanto, exprimir o Direito em regras escritas.

Seguiu-se a fase do Direito escrito que outra coisa não foi senão a procura de meios mais esplícitos para a consecução do fim jurídico. Experimentava-se; dessa maneira, a sensação de segurança no trato dos negócios jurídicos. Essa sensação, porém, não teve maior duração, uma vez que o sistema passou a demonstrar a sua falha, repetindo-se a incerteza ante o amontoado de leis esparsas, vigorantes umas e outras não.

A tendência codificadora exprimiu-se naquela antecipação em que os romanos tiveram a preocupação de reunir tal legislação, de digerir o que se havia erigido em lei escrita para se saber, por fim, o que realmente constituia Direito a ser acatado. Em última análise, quiseram êles ter certeza no seu Direito.

Isso tudo demonstrava a nossa vocação para a legislação, como bem acentuou depois Savigny. Essa vocação não obstante era a orientação para caminhos mais largos, para rumos mais positivos, mais certos, afim de se exprimir um Direito, que importasse em meio seguro para a convivência humana.

Lopes Oñate, tratando do tema em foco na sua obra "A Certeza do Direito", assevera que a exigência da certeza da noram, isto é, da lei e, consequentemente, da certeza do Direito, se há sentido sempre como indispensável para a convivência social ordenada.

Quando os romanos apelarem para os seus doutores, investidos da nobilitante função de jurisconsulto, para que triturassem, digerissem nos "Digestos" tôda aquela massa infórme de leis, não pensaram êles senão de se alcançar o necessário equilíbrio das forças vivas da sociedade, premunindo-as de instrumentos legais capacitados para apontar as verdadeiras diretrizes ao comportamento do homem.

Assim sendo, iniciou-se a tarefa codificadora, eis que a massa legislativa estava eivada de êrros, com falta de unidade, gerando a insegurança no meio social, precatado pelo Direito. 
o Código moderno foi - não há negar - a mira mais segura para a vida em sociedade, de vez que nêle se dispôs o Direito, tal como deve ser, tal como deve ser aplicado, resumindo - Código um conteúdo jurídico certo, uma garantia para as sociedades modernas.

Como se acaba de ver, o Direito deixava de ser um problema de verdade para se transformar em um instrumento de conquistas, na vida real, porque o homem visa, simplesmente, através do Direito, a realidade colhida na experiência social de todos os dias.

Se pecado houve aos que entenderam ou entendem, até hoje, o Direito Natural como verdade irretorquível foi o de se ter desprezado a experiência social como fator complementar à realidade jurídica.

Do período historicista para cá, como reação aos excessos racionalistas na concepção do Direito, sentiu-se essa tendência realista do jurídico que passou a ser tratado como fruto único do empírico, como fato social, resumindo tudo nesse realismo brutal, culminado na orientação da Jurisprudência Sociológica de um Holmes, James e Roscoe Pound.

$\mathrm{E}$ vamos ver um neocriticista do porte de Stammler, buscando no conhecimento do que fôsse jurídico, um fim real. Superando Kant, ou, como querem, sendo mais Kant do que o próprio filósofo de Koenigsberg, o doutrinador alemão passa a demonstrar que o jurídico é verdade que possibilita a experiência social.

Emprestando o instrumentalismo crítico da razão pura teorética para o conhecimento também do jurídico, o neokantista de Marburgo não teve em mirt senão desejar ao Direito aquêle fundo realista de certeza, o que iremos ver constatado na sua retumbante doutrina do Direito Natural de conteúdo variável.

Ingressaram, finalmente, os povos num período de Direito escrito e codificado. Os resquícios de um sistema costumeiro não impediram a formação de um quadro positivo de normas codificadas acolhido por quase todos os povos do globo. 
Quando o jurídico atinge a sua maturidade científica, desde que já demonstramos, de início, a sua aparição num sentido acientífico, volve-se à angustiosa indagação de sua certeza. Esta é a grande problemática dos sistemas jurídicos hodiernos. As normas, por suas constantes e naturais insuficiências, fazem com que se alarguem, cada vez mais, os horizontes de sua interpretação. O aplicador da lei assume, sempre, papel de maior relêvo no campo do Direito, desde que se investe da alta função criadora na órbita legal.

A interpretação passou a constituir nova fonte de criação jurídica. Os fatos humanos, por sua contingência, seriam incomportáveis nos conteúdos das normas se não fôssem estas consideradas, em face de doutrina corrente, meras formas, em sentido Kantiano, a possibilitarem experiências jurídicas possíveis, ou no dizer de Kelsen, verdadeiros juizos hipotéticos, aptos à apreensão, na sua imensa variedade, da conduta humana.

$\mathrm{E}$, neste caso, a interpretação jurídica seria o conhecimento, não do conteúdo das normas como se entendia na doutrina tradicional, mas como quer o kelsenista Carlos Cóssio (*), da conduta em face da norma, num processo a que o jurista argentino chama de "empírico-dialético", para que enfim se compreenda o Direito, como cultura que é.

Ora, como bem o afirma Oñate, em sua obra citada, o problema da certeza é o problema do particular, o problema do indivíduo, considerado tal que êle é, rebelde à tôda redução universalista. E a conduta jurídica humana, fazendo-se de modo individual, mais se reflete na certeza do Direito.

O que se pergunta, com muita razão de ser, é se em face de tanta doutrina moderna, o direito alcançou o seu ideal de certeza.

(*) Segundo Miguel Reale, entre nós, Cóssio não é totalmente um adepto de Kelsen. A sua Teoria Egológica do Direito não traz, segundo a opinião do professor paulista, senão $20 \%$ de ingredientes mentais do Kelsenismo. 
O Direito é uma garantia para os indivíduos, uma promessa de certeza como relata Couture. Procura realizar, antes de tudo, o contrôle social.

O problema humano é, todo êle, um problema de convivência. Ora, a Economia, por exemplo, que se arroga como criadora de soluções sociais, não dá ao Direito senão a prerrogativa de epifenômeno.

É bem verdade que a Economia diz de perto tal convivência humana. Porém, quem a estabelece - não há de se ter dúvidas - não é a Economia, ao contrário do que entendem os marxistas, e sim o Direito. É êste que estabelece as condições de vida em sociedade e onde, naturalmente, irão travar as relações econômicas, tão necessárias à existência social.

Não é sem ousada precipitação de querer dar fecho a êstc pequeno trabalho que afirmamos ser debalde desejar encontrar-se paz, segurança, ordem, enfim, justiça, como valores jurídicos plenamente realizáveis na convivência dos homiens, enquanto não se considerar a natureza divina do problema humano e que, assim, só se resolve verdadeiramente pela fé e pela compreensão. 